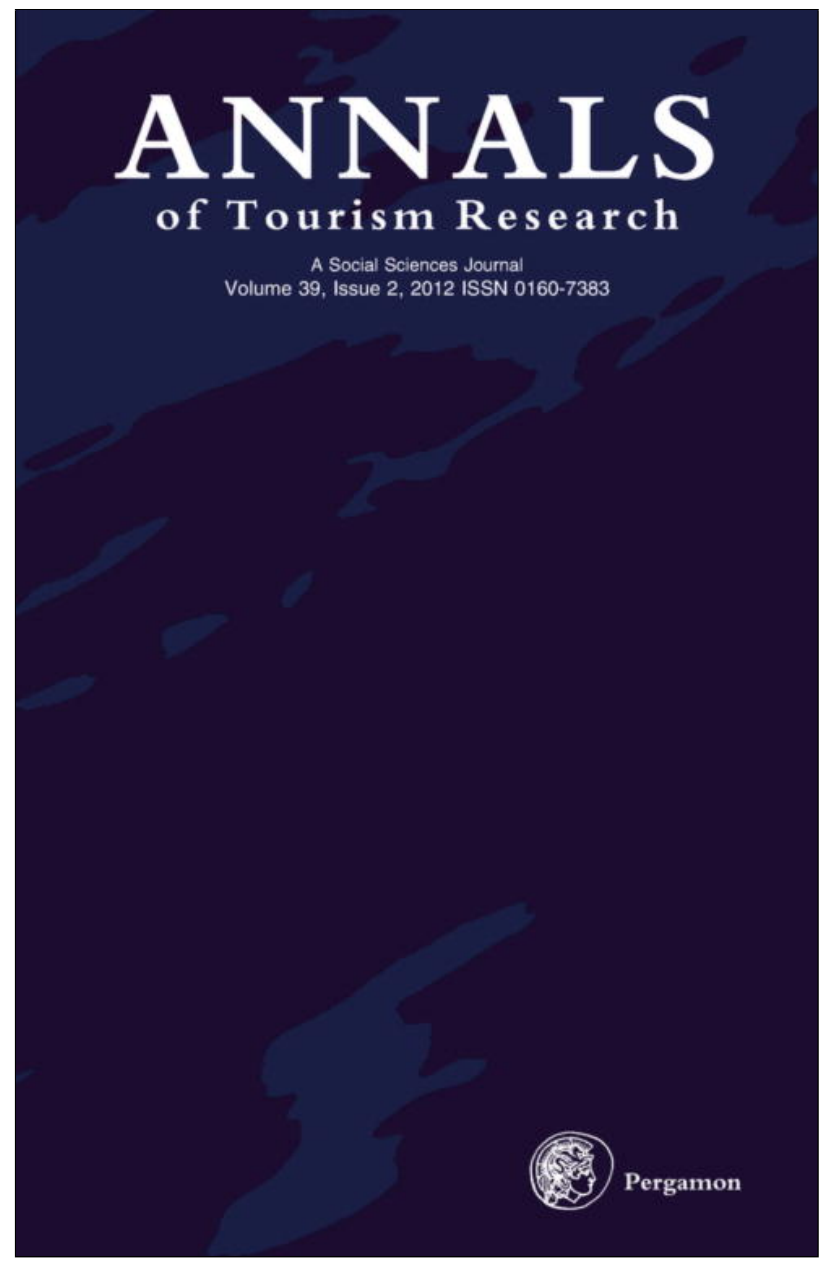

This article appeared in a journal published by Elsevier. The attached copy is furnished to the author for internal non-commercial research and education use, including for instruction at the authors institution and sharing with colleagues.

Other uses, including reproduction and distribution, or selling or licensing copies, or posting to personal, institutional or third party websites are prohibited.

In most cases authors are permitted to post their version of the article (e.g. in Word or Tex form) to their personal website or institutional repository. Authors requiring further information regarding Elsevier's archiving and manuscript policies are encouraged to visit:

http://www.elsevier.com/copyright 


\title{
THE IMPACT OF SEARCH COST REDUCTION ON SEASONALITY
}

\author{
Federico Boffa \\ University of Macerata, Italy \\ Institut d'Economia de Barcelona, Spain \\ Marianna Succurro \\ University of Calabria, Italy
}

\begin{abstract}
This study explores how online booking affects seasonality, measured as the variation in hotel bed-places net occupancy rate between peak and off-peak periods. We first develop a formal model illustrating that, as a result of the reduction in search costs brought about by the internet, competitive pressure strengthens. This effect is stronger in the peak period than off-peak, thus leading to an increase in seasonality associated to online booking. We then test our finding in a sample of 18 countries over the 1997-2007 span; the empirical results support the notion that the use of the internet causes an increase in seasonality. A set of policy implications conclude the work. Keywords: internet, search costs, net occupancy rate, seasonality. (C) 2012 Elsevier Ltd. All rights reserved.
\end{abstract}

\section{INTRODUCTION}

This paper studies the relation between the reduction in tourists' search costs due to online booking and the variation in bed-places net utilisation between peak and off-peak periods. Search costs and direct online organisation of the trip are two prominent aspects of the tourism industry that have been deeply affected by recent technological advances.

The tourism industry exhibits a remarkably high degree of product differentiation. Understanding tourists' process of search and information acquisition is therefore key to gaining a deeper knowledge of the industrial dynamics. Technological progress, coupled with regulatory changes, has modified the nature of tourists' search process in at least two directions. First, it has expanded consumption opportunities (for example, by decreasing the cost of reaching relatively far destination),

Federico Boffa (Jesi Branch, Via Angeloni, 3, 60035 Jesi (AN), Italy. Email <federico.boffa@unimc.it $>$ ) is an Associate Professor of Applied Economics in the Department of Legal and Economic Studies at the University of Macerata, Italy, and an Associate Member of several Centres for Research. He specialises in Industrial Organization and Tourism Economics. Marianna Succurro is a Researcher in Applied Economics in the Department of Economics and Statistics at the University of Calabria (87036, Rende (CS), Italy. Email $<$ m.succurro@unical.it $>$ ). Her research areas include Tourism Economics, Industrial Organization and Law and Economics. 
and, as a result, the expected benefit of searching for a tourist destination. Second, it has decreased the costs of direct search, for example through the release of faster and more reliable search tools, thanks to the Internet. The two effects contribute to making the direct online search process less time-consuming and more valuable, hence more productive.

Our paper aims at investigating the impact of these fundamental shifts in the tourists' search process on the seasonal variation in the occupancy rate in hotels.

We first model the tourist search process and we illustrate, within a search framework, how direct booking increases seasonality. An improvement in the search technology decreases the cost associated to a longer search (for example, by replacing a longer and more expensive phone call with a quicker and cheaper internet search); therefore, it can be thought of as decreasing search cost. The decline in search cost induces consumers to search more, until they find a better deal. This, in turn, increases the elasticity of each firm's individual demand, a price reduction effect analogous to that associated to an increase in competitive pressure. We find that in a two-period framework, with a peak period in which consumers have, on average, a higher willingness to pay for the destination than off-peak, the price reduction effect is stronger in the peak than off-peak; as a result, lower search costs increase the difference in occupied bed-places between peak and off-peak seasons. Our model highlights a supply-driven positive association between online booking and seasonality: in the aftermath of online booking, firms modify their pricing strategy, inducing a comparatively larger increase in occupied bed-places in the peak period than off-peak.

The same result holds even when we extend our analysis to allow for agency intermediation. The decline in search costs provides potential tourists with an incentive to undertake a longer search for the most convenient intermediary. This has an effect analogous to an increase in competitive pressure among intermediaries, with the resulting impact on the variation in bed-places occupancy equivalent to the case of direct search.

The empirical analysis supports the conclusions drawn from our formal model. We find that the reduction in the costs of direct search, provided by the amount of direct reservations over the Internet, increases the variation in bed-places net occupancy rate between peak and off-peak periods.

\section{LITERATURE REVIEW}

Our paper relates to three separate strands of literature, respectively the capacity management issue under time-varying demand (i.e., the seasonality issue), the tourist information acquisition process and, finally, the impact of Information and Communication Technology (ICT) on tourism. While each of the three strands is rich and extensive, our paper is the first attempt, to our knowledge, to link the three in a unified framework. 


\section{The Impact of ICT on Tourist Search}

Over the last 20 years, the internet has changed various facets of social life, creating many social concerns (Kim, 2010). An appropriate diffusion of the ICT in the tourism sector improves its social and economic impacts, from which many consumers and organisations can benefit (Minghetti \& Buhalis, 2010). Indeed, the internet has grown to be one of the most effective means for tourists to seek information and purchase tourism-related products (Pan \& Fesenmaier, 2006). This constitutes the starting point of our research.

Some recent studies explore how tourist demographic and trip purpose characteristics influence decision-making strategies for travel (DiPietro, Wang, Rompf, \& Severt, 2007; Hyde, 2008; Pearce \& Schott, 2005; Schmidt \& Spreng, 1996; Woo \& Dong, 2004). They find that factors influencing tourist search include specific characteristics of the vacation-vacation length, destination distance, number of destinations visited, purpose of the trip-and characteristics of the vacationer-age, income and motivational factors, such as need for novelty versus need for relaxation. Other studies analyse the relation between the use of internet and the characteristics of the vacation and the vacationer. In these researches, consumers who book online travels have been identified as those with a higher education, who undertake more frequent international travel, visit travel websites and general websites more often, and have more positive attitudes towards use of the Internet (Morrison, Jing, O'Leary \& Cai, 2001). Even amongst well-experienced consumers, there exists a group who do not book online; these non-users of Internet booking tend to be aged 60 plus years, people who seldom shop electronically, and seldom shop from the home or office (Card, Chen, \& Cole, 2003).

As far as the impact of ICT on tourism is concerned, it is recognised that Internet is an important external source since more and more consumers use online information for their decisions at a relatively low search cost. Although it is easy to gather information about a destination or a specific product/service from the Internet, consumers still have to spend time, pay for internet service or booking, and invest a significant amount of effort in processing what they find. It is likely that, because of low cost and ease of retrieving the information from online sources, more and more consumers will make more external effort (Gursoy \& McClearly, 2004). That is the reason why the goal of the destination managers and marketers is to make external search as inexpensive and time efficient as possible by avoiding websites that are difficult to navigate, are linked to empty sites or have incomplete information. Some researches explicitly aim at examining consumers' perspectives of the information role of the Destination Marketing Organisations (Choi, Lehto, \& Oleary, 2007); other studies have been conducted to measure the effectiveness of destination Marketing Organisations' websites (Li \& Wang, 2010).

Given the increasing use of technology by the tourists, the Destination Marketing Organisations and the services suppliers, it is interesting to investigate the impact of new technology sources on search 
costs. The industrial organisation theory on consumer search under asymmetric information is widely developed. Two contributions are worth mentioning. Stiglitz (1989) provides a comprehensive overview, where he shows that equilibrium may fail to exist in perfect competition models under search costs. He also illustrates that, under a framework of imperfect competition, search costs increase firms' rent. Bakos (1997) finds that the reduction in search cost improves efficiency, by increasing the competitive pressure. Bakos' results represent the driving force behind the results of our formal model. Our analysis, indeed, builds on this point, and, in the theoretical section, shows how the reduction in search costs alters the consumers' behaviour in the information acquisition process.

As it is known, sources of tourism information can be classified in terms of whether the source is commercial or non-commercial (source of information) and received from personal or impersonal communication (type of information) (Fodness \& Murray, 1997). A multiplicity of information sources and decision strategies are available to the contemporary tourist.

\section{The Tourist Information Acquisition Process}

Our paper contributes also to the literature on the tourist information acquisition process. It is widely recognised that understanding search behaviour of leisure tourists is vital to both tourism scholars and practitioners (Snepenger, Meged, Snelling, \& Worrall, 1990). Gursoy and Chen (2000) show that, given the high uncertainty and dynamics of the tourist market, understanding how tourists acquire knowledge is important for marketing and management decisions, the design of effective communication campaigns and service delivery.

The dynamic consumer decision making process has been extensively analysed, both before the trip and while at the destination. Several studies investigate the factors which may lead to either more or less information search, underlying the role of several aspects of the environment (such as difficulty of the choice task, number of alternatives, complexity of the alternatives) and situational variables (such as previous satisfaction, time constraints, perceived risk) (Fesenmaier \& Jeng, 2000; Fodness \& Murray, 1997. 1998, 1999; Gursoy \& Chen, 2000; Gursoy \& McClearly, 2004; Jeng \& Fesenmaier, 2002; Moutinho, 1987; Sirakaya \& Woodside, 2005; Van Raaij, 1986). The literature has emphasised essentially three major factors influencing tourist information search: motives (McIntosh \& Goeldner, 1990; Raitz \& Dakhil, 1989), determinants (Engel, Warshaw, \& Kinnear, 1991; Snepenger et al., 1990; Van Raaij, 1986) and sources (Engel, Blackwell, \& Miniard, 1995). With respect to information sources, one fundamental classification is internal vs. external search. Internal search is essentially based on the retrieval of knowledge from memory, while external search consists of collecting information from the marketplace. As reported in Fodness and Murray (1997) and Gursoy and McClearly (2004), search may take place, and almost always does initially, internally, such as when past experiences 
are used as the basis for planning a repeated visit to a destination. If the contents of memory are not sufficient for decision making, however, search activities extend out into the external environment. In the case of vacation travel, the search is often predominantly external, involving considerable effort and a variety of information sources; that's the reason why our paper focuses on external search.

The tourist has a wide choice of external sources (Engel et al., 1995) that can be used prior to departure, in transit and once at the destination (DiPietro et al., 2007) for core, secondary and en route decisions (Fesenmaier \& Jeng, 2000; Hwang \& Fesenmaier, 2004). Tourists are posited to be highly involved in the decision-making process, and this is, at the least, partially due to the high costs and uncertainty associated with the services to be received. Tourism is an experience good and, as it emerges from the economics of information theory (Stigler, 1961), tourists are likely to search as long as they believe that the benefits of acquiring information outweigh the costs. The total cost of a given search strategy can be partitioned into three separate components: time spent, financial cost and effort required (Gursoy \& McClearly, 2004; Vogt \& Fesenmaier, 1998). Time spent in search, which is more valuable for people with a higher opportunity cost of time, is considered the most important component of external search cost, followed by the monetary costs of the search (phone calls, transportation, fax, online connection, etc.). Contemporary internet technologies have provided an additional channel through which bookings can be made with minimal effort (Hyde, 2008).

Our paper finds that, as a result of the decrease in search cost brought about by the internet, consumers search more; specifically, they increase the value they can draw from the offer.

\section{Tourism Seasonality}

Tourism seasonality is an interesting and multifaceted subject area which has received a great deal of attention in academic research, policymaking and management, especially in recent years. Amongst the various aspects considered are the definitions and approaches to measuring seasonality, its causes and impacts, policy-related issues and studies into consumer behaviour.

The concepts, theory and definitions, as well as the impacts and perceptions of seasonality, are explored by Butler (1994), Butler and Mayo (1996) and Hinch and Jackson (2000); links between demand fluctuations and tourist motivations are studied by Calantone and Johar (1984), Manning and Powers (1984) and Spotts and Mahoney (1993). Overviews of different methods for quantifying seasonal variations are presented by Drakatos (1987), Koenig and Bischoff (2003) and Lundtorp (2001), and quantitative techniques to investigate demand variations in the accommodation sector are applied by Jeffrey and Barden (1999) and Sørensen (1999).

Causes and forms of seasonality have been identified in several studies (Bar-On, 1975; Butler, 1994; Capò-Parrilla, Font, \& Nadal, 2006; 
Cuccia \& Rizzo, 2010; Frechtling, 1996). These authors distinguish different causes of seasonality in tourism. The natural causes relate to regular temporal variations in natural phenomena, particularly those associated with climate and the period of the year. Tourists have specific preferences, which make it necessary to distinguish between different purposes of tourism (such as sun and sea, hiking, ski vacations, and conferences). Natural causes are beyond the control of decision-makers. The institutional causes depend on social factors and policies concerning specific customs and legislated holidays. They include school schedules, public holidays, festivals (religious and cultural), and other events that, even today, are usually based on historic conventions.

The empirical literature on the economic determinants of tourism seasonality looks at both the demand and the supply side. The research on the seasonal variation of tourism demand focuses on tourists' income, relative price, exchange rate and substitutes prices (RossellòNadal, Riera Font, \& Rossello, 2004), consumer demographic characteristics and preferences, social and cultural interests (Cellini \& Cuccia, 2007; Fernandez-Morales \& Mayorga-Toledano, 2008; Jang, 2004; Spencer \& Holecek, 2007). The empirical research on the seasonal variation of tourism supply focuses on the characteristics of accommodation facilities (Capò-Parrilla et al., 2006; Koenig \& Bischoff, 2004). These studies find that the high quality of tourism services and the location in the historical centre lessen the seasonal variation in the occupancy rate.

The published research on seasonality impacts is also extensive. Some studies focus on private costs. Private producers suffer from declining returns on investment, a high level of under-exploited capacity and fixed costs in the off-seasons (Bar-On, 1993, 1999; Cuccia \& Rizzo, 2010; Sutcliffe \& Sinclair, 1980). The final consumers of the destination pay higher prices in the peak-season. The workers in the tourism sector typically accept seasonal jobs, without the usual protection required by labour contracts, and long periods of unemployment (Ashworth \& Thomas, 1999; Bar-On, 1993, 1999; Krakover, 2000). Other studies focus on negative externalities, therefore on the social costs of seasonality that concern local public utilities, the management of public goods and services such as infrastructures, public safety, public health (Murphy, 1985), and natural resources (Manning \& Powers, 1984). Capò-Parrilla et al. (2006) argue that, when the number of tourists exceeds accommodations and facilities capacity, a reduction in the quality of the services can occur owing to congestion, overbooking, or saturation with subsequent reduced satisfaction level. Cuccia and Rizzo (2010) claim that seasonality generates private and social costs that usually largely exceed its small benefits.

Several studies attempt to identify a set of policies aimed at reducing seasonality. From a demand perspective, Capò-Parrilla et al. (2006) distinguish between the policies designed to lessen seasonality and those intended to reduce its negative impact. To lessen seasonality, policy-makers might encourage off-season tourism, by implementing strategies that allow to capture the differentiation in tourism demand (based on cultural, religious, sports, business tourism). Events and festivals are the most commonly used strategies to increase demand outside the peak 
season (Baum \& Hagen, 1999; Getz, 1991, 1997; Higham \& Hinch, 2002), along with the organisation of conferences and business meetings aimed at attracting business tourists (Baum \& Hagen, 1999; McEnnif, 1992). Another popular strategy has been the so-called contra-seasonal pricing policy (Butler \& Mayo, 1996; O'Driscoll, 1985; Weaver \& Oppermann, 2000), that is a peak-load pricing policy. According to Capò-Parrilla et al. (2006), in order to reduce the negative effects of seasonality in the interest of future generations, policy-makers should determine the optimal degree of seasonality, depending on each destinations' carrying capacity. In the interest of the present generation, different tools can be used, from direct monetary instruments, such as the introduction of a tourism tax on arrivals or presence, to nonmonetary ones, such as the regulation of tourism flows (rationing) in very extreme cases of fragile heritage and natural sites (Cuccia \& Rizzo, 2010). From a supply perspective, strategies for reducing seasonality are more limited and focused exclusively on policies oriented to reducing negative effects, such as expanding current capacity, creating new facilities or utilising external resources (Capò-Parrilla et al., 2006).

As it has been illustrated, tourism seasonality has received great attention in recent years. For the accommodation sector, in particular, the relatively high fixed costs make seasonality a particularly important issue. Low variability and an extended main season are generally regarded as desirable goals. However, the factors that explain yearly demand fluctuations beyond the climatic or institutional and social ones have not been analysed that extensively. Some studies focus attention on the role of the Internet by providing strong support for the idea that the web represents an essential marketing tool for accommodation businesses. Koenig and Bischoff (2004) find that both the low-occupancy and the poor performing clusters exhibit a highly statistically significant correlation with a weak presence on the internet. Therefore, high occupancy and high performance would be associated to structures offering online reservation systems. Other studies have found that, despite efforts to reduce peaks, monthly seasonality has, in fact, increased in some destinations with the rapid development of tourism (Bar-On, 1975; Butler, 1994). Therefore, the empirical investigation on the role of the internet on the seasonal variation in the occupancy rate commands additional research.

Indeed, as Hinch and Jackson (2000), Koenig-Lewis and Bischoff (2005) and Lundtorp (2001) point out, tourism seasonality research lacks a sound theoretical framework and adopting a more formal and quantitative perspective might facilitate and accelerate progress in this field.

Our paper, which includes both an empirical and a theoretical analysis, aims at contributing to fill the gaps currently existing in the literature on seasonality. More specifically, it is an attempt to bridge the three strands of literature, shading light on how ICT, by boosting online booking, modifies the information acquisition structure of consumers and their process of accommodation selection. This, in turn, commands a change in the pricing structure of the firms, which ultimately has an impact on seasonality. This study explores, in 
particular, the effects of specific impersonal online tourism information sources-both commercial and non-commercial, public or private-on search costs and occupancy rates. In particular, the purpose of the research is to check how new technology and direct online booking affect the difference between peak and off-peak occupancy rate of bed-places in hotels and similar establishments. By developing a formal model, this article offers a contribute to the lack of theoretical framework on the possible determinants of seasonality. The conclusions of our model are supported by our empirical results.

\section{A FORMAL MODEL}

The model we develop in this section aims at illustrating the incentives at work in determining the relation between search costs and variation in bed-places occupancy rates. The basic intuition follows the line of Bakos (1997) and stresses the increase in competitive pressure resulting from a reduction in search costs.

Our model adopts the product search theory framework and builds on Spulber (1996), extending it to a two-period setting.

While we will not elaborate on the technicalities of the model in the paper (available upon request), we illustrate the setting, the main steps we followed to solve it and we finally state the results.

We assume consumers assign a value to a tourism destination in two different seasons (denoted $s$ : peak, or high season (denoted $h$ ), and off-peak, or low season (denoted $l$ )).

Valuations differ across consumers and across seasons. In any given season, the valuation is uniformly distributed across consumers in the $v^{s}, \bar{v}^{s}$ interval; however, $\bar{v}^{h}>\bar{v}^{l}$, reflecting our assumption that, in the peak period, a larger number of customers is potentially interested in the destination, and on average a higher value is attributed to the destination in the peak time.

Consumers interested in spending time at the destination must search for an accommodation. Search is time-consuming and consumers discount the future at a rate $\delta$. the discount rate reflects the additional (opportunity) costs involved in each subsequent round of search. Under a higher discount rate, consumers' benefit from waiting (with the prospect of finding a lower price) decreases. If search turns out to be less time-consuming, then the opportunity cost involved in each additional round of search declines. Therefore, a reduction in the search costs-something brought about by the Internet-is reflected, in the model, by a decrease in the discount rate.

Hotels differ in their cost structure. The heterogeneity may reflect different quality levels. $k$ is uniformly distributed in the $(0,1)$ interval.

As it is standard in this framework, we assume that consumers visit a single hotel per period. They have perfect information on the hotel price distribution, although they do not know which hotel they will be matched with at each round; after getting to know the price charged by that hotel at a given quality level, they have to decide whether to choose it, or to keep searching for a better alternative (thereby 
incurring additional search costs), going through an additional round of search, where they will face exactly the same problem of the previous period. Therefore, in each round, consumers trade off future benefits, in terms of prospects of cheaper alternatives, to additional search costs. Consumer's recursive strategy is therefore based on an endogenously determined reservation price-that is, a threshold price below which consumers accept the offer and stop searching.

We solve the recursive equation, and identify the reservation price $r$ as a function of the hotels' price distribution. We find that

$$
\begin{gathered}
\frac{\delta r}{\delta v^{h}}>0 \\
\frac{\delta r}{\delta v^{l}}>0
\end{gathered}
$$

The reservation price, both in the peak and in the offpeak seasons, increases as the maximal (and, as a consequence, average) willingness to pay for the destination increases. We also find that the reservation price increases as the discount factor increases; this is consistent with the intuition that, as search costs increase, consumers are less prone to search, and more inclined to accept higher prices.

Hotels face a problem that mirrors the consumers' problem. They know the distribution of consumers' valuation, but they do not know which consumer they are faced with at each round. Each firm charges a price, and faces an expected demand at each round. We derive the expected demand for each firm as a function of the price it charges. We can show that such demand function exhibits the usual negative relation between price and quantity.

Given the above identified demand function, each firm chooses the optimal price that depends on its cost $k$ which, as a reminder, is uniformly distributed in the $(0,1)$ interval. We identify the prices chosen by each hotel as a function of the consumers' reservation price. As expected, the price charged increases with cost.

We are then ready to characterise the equilibrium of the game, constituted by a price charged by each firm and a reservation price chosen by each consumer such that no consumer and no firm have an incentive to deviate. To that end, we combine the equilibrium condition for the consumers (i.e., reservation price as a function of the hotel rooms price distribution), and the equilibrium condition for the hotels (i.e., room price as a function of consumers' reservation price).

The equilibrium results are the following:

$$
\begin{aligned}
\hat{p}^{l} & =\frac{2 \delta}{4 \delta+1} \\
\hat{p}^{h} & =\frac{4 \delta}{4 \delta+1} \\
\bar{p}^{l} & =\frac{4 \delta}{4 \delta+1} \\
\bar{p}^{h} & =\frac{8 \delta}{4 \delta+1}
\end{aligned}
$$


where $\hat{p}^{l}$ is the price charged offpeak by the hotel with the lowest cost $(k=0), \hat{p}^{h}$ is the price charged in peak by the hotel with the lowest cost $(k=0), \bar{p}^{l}$ is the price charged offpeak by the hotel with the highest cost $(k=1)$, and finally $\bar{p}^{h}$ is the price charged in peak by the hotel with the highest cost. Prices in the high season exceed prices in the low season, as a result of the higher reservation prices in the high season, stemming from the higher average willingness to pay.

After solving for the reservation price, we obtain the aggregate quantities (i.e., the number of active customers), offpeak and in peak, respectively:

$$
\begin{aligned}
& Q^{l}=1-\hat{v}^{l}=1-\hat{p}^{l}=1-\frac{2 \delta}{4 \delta+1}=\frac{2 \delta+1}{2 \delta+1} \\
& Q^{h}=2-\hat{v}^{h}=2-\hat{p}^{h}=2-\frac{4 \delta}{4 \delta+1}=\frac{4 \delta+2}{4 \delta+1}
\end{aligned}
$$

Observe that, as intuitively plausible, an increase in search costs reduces the number of active customers, since $\frac{\partial Q^{l}}{\partial \delta}<0$ and $\frac{\partial Q^{n}}{\partial \delta}<0$.

The difference between peak and off-peak number of active consumers is:

$$
\Delta^{h, l}=\frac{4 \delta+2}{4 \delta+1}-\frac{2 \delta+1}{4 \delta+1}=\frac{2 \delta+1}{4 \delta+1}
$$

The sensitivity of the difference between high and low season output is as follows:

$$
\frac{\partial \Delta}{\partial \delta}=\frac{2(4 \delta+1)-4(2 \delta+1)}{(4 \delta+1)^{2}}=\frac{-2}{(4 \delta+1)^{2}}
$$

We have therefore established the following:

Proposition 1. The difference between high season and low season output increases as the discount rate decreases.

\section{The Proposed Model and Discussion}

Some comments on the results are in order. In this setting, a search cost reduction alters the trade-off in each round of search, by increasing the relative desirability of continuing search; this is reflected in a decrease of consumers' reservation price. The decline in consumers' willingness to pay, along with a surge in local elasticity, triggers a reduction in firms' price.

As the discount rate reflects the opportunity costs associated to each additional round of search, a higher discount rate corresponds to a higher search cost. The web, by making any additional rounds of search cheaper, reduces the discount rate. The theoretical results apply straightforwardly to direct search. They show that, if the discount rate drops (for example, due to Internet and the availability of easy-to-use price comparison websites), the difference in capacity utilisation in the peak period and off-peak increases. The result is based on the following mechanism. A low discount rate decreases the reservation value 
and increases the expected length of the search process. This increases the price elasticity of each firm's individual demand. As a consequence, the total quantity increases in both periods. In other terms, a lower discount rate induces higher competition among tourism operators. Under our (commonly adopted) functional form assumptions, the difference between high and low season quantities increases with the level of competition, and this represents the driving force behind our result.

Our findings could extend to agency reservations. A decline in the search cost decreases the cost of visiting additional online agents; this increases competition among agents and an analogous mechanism to that applicable for direct search emerges.

\section{EMPIRICAL ANALYSIS}

\section{Methodology and Data}

The empirical analysis aims primarily at testing the hypothesis derived from our formal model that online booking entails an increase in seasonality (baseline model); we then add a matrix of control variables, in order to investigate more generally the determinants of the seasonal variation in occupancy rates; finally, we include a set of instrumental variables to check the robustness of our results. Our sample includes 18 European countries, chosen on the basis of available data, over the 1997-2007 years. The list of countries is reported in Table 1.

Our goal is to verify whether, and to what extent, differences in the use of the internet by consumers for direct reservation with the transport/accommodation operator explain variations in bed-places net occupancy rate in hotels and similar establishments.

Our baseline model, where we directly test Proposition 1 derived from our formal model, takes the following form:

$$
\begin{aligned}
& \triangle O C C_{i t}=\beta_{0}+\beta_{1} e O R G_{i t}+\gamma_{t}+u_{i}+\varepsilon_{i t} \\
& t=1997, \ldots, 2007, \quad i=, \ldots, 18 \text { countries }
\end{aligned}
$$

where $\gamma_{t}$ indicates time effects, $u_{i}$ indicates countries' effects, $\varepsilon_{i t}$ is the stochastic residuals. Our dependent variable $\triangle O C C_{i}$ is the coefficient of

Table 1. List of countries

\begin{tabular}{ll}
\hline Belgium & Luxembourg (Grand-Duché) \\
Czech Republic & Netherlands \\
Denmark & Poland \\
Germany (including ex-GDR from 1991) & Portugal \\
Ireland & Slovenia \\
Greece & Slovakia \\
Spain & Finland \\
France & United Kingdom \\
Italy & Norway \\
\hline
\end{tabular}


variation in bed-places net occupancy rate. We use monthly data on bed-places net utilisation, drawn from the Eurostat database. The net occupancy rate of bed places in a given month is the ratio of total overnight stays to the product of the bed places on offer and the number of days in which the bed places are actually available for use (net of temporary closures for decoration, by police order, etc.). When measured on monthly basis, variations in the occupancy rate can be used to measure seasonal patterns (Kandari \& Chandra, 2004).

Our independent variable $e O R G_{i}$ indicates the rate of online direct reservation with the transport/accommodation operator over the total number of trips in country $i$. As the Internet reduces search cost, this variable, which measures the amount of online booking, proxies a decline in the average search cost (Data source: Eurostat).

Our panel data regression, aimed at investigating more thoroughly the determinants of seasonality (of course, still with a focus on the impact of online booking) includes additional control variables:

$$
\begin{aligned}
\Delta O C C_{i t}= & \beta_{0}+\beta_{1} e O R G_{i t}+\beta_{2} A r_{i t}+\beta_{3} B_{i t}+\beta_{4} A i r p_{i t}+\beta_{5} L C_{i t} \\
& +\beta_{6} C_{i t}+\beta_{7} O r_{i t}+\beta_{8} X_{i t}+\beta_{9} g d p_{i t}+\gamma_{t}+u_{i}+\varepsilon_{i t}
\end{aligned}
$$

The matrix of control variables is designed to disentangle the impact of the diffusion of the internet from that of other factors that can possibly affect seasonality, including the fact that different countries may follow different seasonal patterns.

$A r_{i}$ controls for total tourist arrivals in country $i$. It is computed as total arrivals of residents or non-residents checking in at a hotel or a similar establishment (Data source: Eurostat). $B_{i}$ is a proxy of the average size of the accommodation structures in country $i$. It is computed as the ratio of the total amount of bed-places to the total number of hotels and similar establishments in country $i$ (Data source: Eurostat).

The two explanatory variables above identify whether, and to what extent, seasonality depends on the volume of inbound tourism and/ or on the average size of the establishments. They have been included to investigate if two structural characteristics of the tourism sector matter for the seasonality phenomenon.

The variables $A i r p_{i}$ and $L C_{i}$ control for the tourists' incentives to travel by airlines, the transportation mean which has been most affected by the increase in the use of Internet by consumers (Dana \& Orlov,

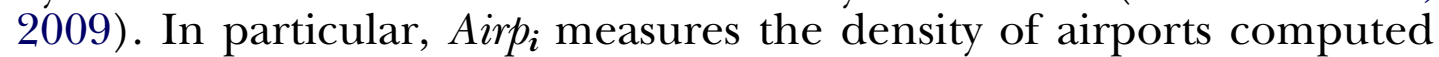
as the ratio between total number of civil airports in each country (Data source: International Air Transport Association) and total area $\left(\mathrm{km}^{2}\right)$ (Data source: Wikipedia). The higher the density, the lower (higher) the average distance (incentive) to reach the chosen destination. $L C_{i}$ indicates the presence of low cost airlines in country $i$, measured as the ratio between the total number of low cost airlines flying from/to country $i$ (Data source: flylowcostairlines.org) and the total number of airports. The percentage of low cost flights has shown impressive growth since liberalisation of air transport in Europe. As several low cost companies restrict their offer to/from specific destinations to a limited period of the year (i.e. from June through August) 
(EUROCONTROL, 2007), it is reasonable to formulate an hypothesis that their presence significantly affects seasonality.

The explanatory variable $C_{i}$ has been included in order to take into account the phenomenon of flows concentration. A concentrated flow indicates that a large amount of tourism inflows comes from few origin countries; on the other hand, a dispersed flow means that tourists inflow is more evenly distributed across various origin countries. The level of flow concentration may impact seasonality, as, in principle, the pattern of seasonality of tourism outflows may vary across different origin countries. Therefore, destinations in which inbound tourists are concentrated in few origin countries may be more subject to the specific seasonality patterns of tourism outflows of such countries; in other words, countries with different flow concentrations may experience different seasonality patterns. The flow concentration index has been measured as a sum of the square of each origin country inflow share on the total number of tourists reaching the destination. Specifically, for each destination country, we first compute the percentage of tourists coming from each of the 18 countries in our sample, then we square each percentage, and finally sum them up. This measure is analogous to the Herfindhal Hirschman index, often employed to measure market concentration (see, for example, Tirole, 1988, pp. 221-223) (Data source: Eurostat).

Additionally, our control matrix directly includes variables concerning the main origin countries and transport providers. As for almost half of the analysed countries, Germany represents the main tourists' origin country, $O r_{i}$ is a dummy variable which is equal to 1 if the main origin country is Germany, 0 otherwise (Data source: Eurostat). Observe that whether Germany is the main origin country or it is not is not correlated to the above discussed flow concentration; therefore, we do not run into collinearity issues. The matrix $\mathrm{X}$ explicitly includes the breakdown of trips by mode of transport (\%) as reported by Eurostat (Statistics in Focus, several years). We consider all transport means (air, rail, coach and water-way) different from private vehicle, which is the most popular mean of transport for all European countries. More specifically, the matrix includes three dummy variables defined as follows: $\mathrm{D}_{\mathrm{r}_{-} \mathrm{i}}$ equals 1 if the rail transport is relatively more important than air transport for country $i, 0$ otherwise; $\mathrm{D}_{\mathrm{c}_{-} \mathrm{i}}$ equals 1 if the coach transport is relatively more important than air transport for country $i, 0$ otherwise; $\mathrm{D}_{\mathrm{w}_{-} \mathrm{i}}$ equals 1 if the water transport is relatively more important than air transport for country $i, 0$ otherwise. We included this variable in the analysis, as the market structures and the cost functions of different modes of transport may generate different seasonality patterns. For example, the economies of scale involved in sea transport may contribute to an increase in seasonality in destinations that are mainly accessible by sea.

Finally, we included the Gross Domestic Product growth rate in order to estimate the impact of the macroeconomic context on bedplaces net occupancy rate. One can assume that a dynamic economy, with a relatively high growth rate, is characterised by a higher percentage of business travelers and off-season cultural events (like 
conferences, fairs, festivals, etc.) which could contribute to mitigate the seasonality phenomenon (GDP data source: International Monetary Fund).

Table 2 illustrates summary statistics.

\section{Econometric Findings}

The results of equations (1) and (2) estimation over the 1997-2007 years are reported in Table 3 . We first test the baseline model by including only $e O R G$ as predictor (Table 3 , reg. (0)). The empirical evidence shows that direct online reservation increases significantly (at $1 \%$ level) the coefficient of variation of bed-places net occupancy rate. Therefore, the use of internet for direct booking is positively associated with seasonality.

We can argue that, since it is reasonable to assume that the average occupancy rate has increased over time and, at the same time, the seasonal variation in the occupancy rate has increased due to the direct online organisation, the peak-season occupancy rate has grown at a higher rate than that of the off-peak season.

Additional predictors, included in a second stage of our test, confirm that the inclusion of these extra-variables improves the quality of our estimation. These robustness check include the F-test, the BreuschPagan test, and the Hausmann specification test. The F-test rejects the null hypothesis that all the coefficients are jointly equal to zero at $1 \%$ level (Table 3, reg.(1)), while the combination of the BreuschPagan and of the Hausmann tests allows us to claim that the correct specification of the model is random effects.

The variable $e$ ORG is significant at $5 \%$ level with the expected sign, thus confirming our previous econometric results.

The variables $A r_{i}$ and $B_{i}$ enter at $1 \%$ level with the expected negative sign, indicating that both the volume of inbound tourism and the

Table 2. Summary statistics

\begin{tabular}{lllll}
\hline Variable & Mean & Standard deviation & Min & Max \\
\hline Occupancy rate (coefficient of variation) & 0.23 & 0.08 & 0.102 & 0.494 \\
Direct booking & 0.50 & 0.32 & 0.03 & 0.95 \\
Total arrivals & 198603.9 & 180740.4 & 2586 & 632760 \\
Bed places & 521.99 & 622.59 & 14 & 2143 \\
Density of airports & 84.11 & 105.61 & 2 & 388 \\
Low cost Airlines & 20 & 12.07 & 1 & 41 \\
Concentration Index & 0.20 & 0.06 & 0.123 & 0.486 \\
D_origin country & 0.5 & 0.50 & 0 & 1 \\
D_rail transport & 0.16 & 0.37 & 0 & 1 \\
D_coach transport & 0.22 & 0.41 & 0 & 1 \\
D_water transport & 0.05 & 0.23 & 0 & 1 \\
Gross domestic product growth rate & 3.36 & 2.05 & -0.80 & 10.73 \\
\hline
\end{tabular}


Table 3. Occupancy rate and direct online booking

\begin{tabular}{|c|c|c|c|c|}
\hline $\begin{array}{l}\text { Dependent variable } \\
\triangle O C C_{i t}\end{array}$ & $\begin{array}{l}\text { Baseline } \\
(0)\end{array}$ & $\begin{array}{l}\text { Pooled OLS } \\
\text { (1) }\end{array}$ & $\begin{array}{l}\text { Random effects } \\
\text { (2) }\end{array}$ & $\begin{array}{l}\text { GMM system } \\
\text { (3) }\end{array}$ \\
\hline$\Delta O C C_{i t-1}$ & & & & $\begin{array}{l}0.24^{*} \\
(0.027)\end{array}$ \\
\hline$e O R G_{i t}$ & $\begin{array}{l}0.173^{* * *} \\
(0.257)\end{array}$ & $\begin{array}{l}0.179^{* * *} \\
(0.022)\end{array}$ & $\begin{array}{l}0.162^{* *} \\
(0.021)\end{array}$ & $\begin{array}{l}0.157^{\text {*** }} \\
(0.030)\end{array}$ \\
\hline$A r_{i t}$ & & $\begin{array}{l}-0.003^{* * *} \\
(0.000)\end{array}$ & $\begin{array}{l}-0.002^{* * *} \\
(0.000)\end{array}$ & $\begin{array}{l}-0.001^{\text {** }} \\
(0.001)\end{array}$ \\
\hline$B_{i t}$ & & $\begin{array}{l}-0.143^{* * *} \\
(0.013)\end{array}$ & $\begin{array}{l}-0.101^{* * *} \\
(0.030)\end{array}$ & $\begin{array}{l}-0.089^{*} \\
(0.032)\end{array}$ \\
\hline Airp $_{\text {it }}$ & & $\begin{array}{l}-0.070^{* * * *} \\
(0.008)\end{array}$ & $\begin{array}{l}-0.047^{* *} \\
(0.024)\end{array}$ & $\begin{array}{l}-0.053^{*} \\
(0.011)\end{array}$ \\
\hline$L C_{i t}$ & & $\begin{array}{l}-0.014 \\
(0.011)\end{array}$ & $\begin{array}{l}0.001 \\
(0.008)\end{array}$ & $\begin{array}{l}0.004 \\
(0.002)\end{array}$ \\
\hline$C_{i t}$ & & $\begin{array}{l}0.463^{* * *} \\
(0.083)\end{array}$ & $\begin{array}{l}0.140^{* *} \\
(0.070)\end{array}$ & $\begin{array}{l}0.122^{*} \\
(0.045)\end{array}$ \\
\hline$O r_{i t}$ & & $\begin{array}{l}-0.017 \\
(0.01)\end{array}$ & $\begin{array}{l}0.005 \\
(0.025)\end{array}$ & $\begin{array}{l}0.072 \\
(0.014)\end{array}$ \\
\hline D_rail ${ }_{i t}$ & & $\begin{array}{l}0.067^{*} \\
(0.013)\end{array}$ & $\begin{array}{l}0.046 \\
(0.036)\end{array}$ & $\begin{array}{l}0.038 \\
(0.108)\end{array}$ \\
\hline D_coach ${ }_{\text {it }}$ & & $\begin{array}{l}(0.000) \\
(0.010)\end{array}$ & $\begin{array}{l}-0.024 \\
(0.028)\end{array}$ & $\begin{array}{l}-0.066 \\
(0.023)\end{array}$ \\
\hline D_water $_{\text {it }}$ & & $\begin{array}{l}0.215^{* * *} \\
(0.019)\end{array}$ & $\begin{array}{l}0.204^{* * *} \\
(0.051)\end{array}$ & $\begin{array}{l}0.187^{* * *} \\
(0.028)\end{array}$ \\
\hline GDP growth rate ${ }_{i t}$ & & $\begin{array}{l}-0.005^{*} \\
(0.001)\end{array}$ & $\begin{array}{l}-0.008 \\
(0.001)\end{array}$ & $\begin{array}{l}-0.027 \\
(0.059)\end{array}$ \\
\hline Constant & $\begin{array}{l}0.153^{* * *} \\
(0.013)\end{array}$ & $\begin{array}{l}0.112^{* * * *} \\
(0.024)\end{array}$ & $\begin{array}{l}0.156^{* * *} \\
(0.043)\end{array}$ & \\
\hline $\begin{array}{l}\text { R-squared } \\
\text { F test }(a)\end{array}$ & 0.25 & $\begin{array}{l}0.64 \\
29.74^{* * *}\end{array}$ & $\begin{array}{l}0.75 \\
45.30^{* * *}\end{array}$ & \\
\hline Time Effects ( $F$ test) & & 0.24 & $15.15^{* * *}$ & $14.09^{* *}$ \\
\hline Hausman Test & & & 8.93 & \\
\hline Breusch-Pagan Test & & & $127.44^{* * *}$ & \\
\hline Hansen Test ( $p$ value) & & & & 0.34 \\
\hline $\operatorname{AR}(1)$ & & & & $-3.36^{* * *}$ \\
\hline $\mathrm{AR}(2)$ & & & & 0.38 \\
\hline Observations & 198 & 144 & 144 & 118 \\
\hline
\end{tabular}

(a) It refers to Wald test when random effect model is considered. Robust standard errors in parenthesis.

${ }^{*},{ }^{* *},{ }^{* * *}$, for $10 \%, 5 \%$ and $1 \%$ significance level respectively.

average size of accommodation structures contribute to reduce seasonality. This is consistent with the argument that firms' strategies aimed at decreasing the difference between high and low season tourist flows are widely adopted by larger hotels and accommodation structures. This can be motivated both by the economies of scale involved in setting up a sophisticated pricing policy, and by the consideration that the opportunity cost associated with empty rooms in low season increases with the number of available bedplaces. 
The empirical evidence on the variables $\operatorname{Airp}_{i}$ and $L C_{\boldsymbol{i}}$, included to control for the tourists' incentives to travel by airlines, shows that, while the density of airports is significant in reducing seasonality, the presence of low cost airlines in country $i$ has no statistically significant impact on the coefficient of variation of bed-places occupancy rate.

Quite interestingly, the concentration of tourism flows is statistically significant in explaining seasonality. More specifically, the concentration index enters significantly with a positive sign, indicating that countries with less concentrated tourism flows are also characterised by less seasonality. A possible interpretation of the result is that destinations in which inbound tourists are concentrated in few origin countries are more subject to the specific seasonality patterns of tourism outflows of such countries, whereas in countries with more dispersed flows, the aggregation of various different seasonal patterns of tourism outflows reduces the seasonality in the tourism inflows. Therefore, the outcome of spreading tourism flows more evenly throughout the year is reached more easily when the tourism flows are also more widespread across various countries, that is when the concentration index is low.

With reference to the main mode of transport, the only variable that is always significant is the dummy variable concerning the sea transport, which enters positively at $1 \%$ level. The result is likely related to the economies of scale involved in sea transport, which may contribute to an increase in seasonality in destinations that are mainly accessible by sea (namely, islands).

The empirical evidence finally shows that GDP growth rate and the tourists' main origin country are not significant in explaining differences in bed-places occupancy rate among countries.

As an additional robustness check, we have also explicitly considered charter flights and sea transport (as suggested by an anonymous referee). More specifically: 1) to account for specificities induced by the prevalence of charter flights, we excluded three countries with a very high ratio of non-scheduled flights to total traffic (observe that nonscheduled flights mainly include charter flights) (source of data: Eurostat database). The three excluded countries are Slovenia (where $79.8 \%$ of flights were non-scheduled in 2007), Greece (where the proportion is $38.9 \%$ ) and Slovakia (with a proportion of 20.2\%). 2) We have also considered countries where sea transport is predominant, in view of their possible exclusion. Using Eurostat (2006) Statistics in Focus "How Europeans go on holiday", we found that water transport is particularly important in Greece, as it accounts for more than a fifth of all transport (21.1\%). In all of the other countries included in our analysis, the percentage is lower than $7 \%$. We therefore decided that only Greece was a candidate for exclusion based on the sea transport criterion. To summarise, in order to take into account both the previous points, we have excluded from the empirical analysis Slovenia and Slovakia (as a result of the charter flight criterion), and Greece (as a result of both the charter flight and the sea transport criteria). Our empirical results (available upon request) are very similar to those obtained by the estimation of Eq. (2) (except for some minor changes in the significance levels). 


\section{The Endogeneity Problem}

We include a set of instrumental variables to check the robustness of our results, and to provide stronger support to our result that online booking actually determines seasonality. We consider the endogeneity problem potentially affecting our model. Indeed, in principle, the dependent variable and some of the explanatory variables might be codetermined, and this could potentially raise issues of reverse causality (with high seasonality in part determining high online booking). A higher density of airports, for example, could potentially be explained by a high number of business travelers, which, per se, could reduce seasonality. Several approaches can be used to tackle the endogeneity problem. The traditional approach consists in using an instrumental variables regression with external instruments. An alternative approach uses internal instruments by exploiting the panel data structure. More specifically, we use a Generalised Method of Moment estimator (Arellano \& Bond, 1991; Blundell \& Bond, 1998), treating all the explanatory variables as potentially endogenous. Thus, we rewrite Eq. (2) in dynamic terms, as follows:

$$
\begin{aligned}
\Delta O C C_{i t}= & \beta_{0}+\beta_{1} \Delta O C C_{i t-1}+\beta_{2} e O R G_{i t}+\beta_{3} A r_{i t}+\beta_{4} B_{i t} \\
& +\beta_{5} A i r p_{i t}+\beta_{6} L C_{i t}+\beta_{7} C_{i t}+\beta_{8} O r_{i t}+\beta_{9} X_{i t}+\beta_{10} g d p_{i t} \\
& +\gamma_{t}+u_{i}+\varepsilon_{i t}
\end{aligned}
$$

Eq. (3) can be properly estimated through the First Differences Generalised Method of Moment estimator proposed by Arellano and Bond (1991), which uses all the available lags of each independent variable in levels as instruments. However, the levels are poor instruments when variables exhibit strong persistence (weak instruments). For this reason, we employ the estimation of the System of Equations implemented by Blundell and Bond (1998).

The Generalised Method of Moment-System essentially confirms our previous estimation results (Table 3, reg.(3)). The results of the robustness analysis rule out issues of reverse causality, and confirm the causal (positive) relation between online booking and seasonality.

All technicalities, such as the choice of the endogenous variables, the lags and the performed tests are available on request.

It is interesting to compare our results to a recent analysis concerning the relation between seasonality and airfares.

Garrigos-Simon, Narangajavana, and Gil-Pechuan (2010) show, in the context of the London-Alicante market, the trend of airfares, differentiating between peak and off-peak season. Among the various evidences they find, the one most closely related to our paper concerns how price dispersion changes depending on seasonality. They show that traditional carriers exhibit a larger price dispersion in the low season, when they sell most of their tickets at a discount price, than in the peak season, when a much larger portion of the tickets are sold at full price. Their evidence points at an attempt to manage seasonality through a price-discrimination strategy, prescribing more discounts in the low season. While our evidence does not explicitly deal with 
the hotels' pricing policy, we recognise that the use of Internet, while making it easier to fill the hotels in the peak season, could also be used to better manage seasonality through an appropriate pricing policy. Given the economies of scale involved in setting up a sophisticated pricing policy, we believe price discrimination tends to be performed by sufficiently "large" (in terms of revenue or of profit) firms.

\section{CONCLUSION}

Internet is playing a key role in the development of the tourism industry since it encourages people to travel both by improving access to the destinations and by reducing search costs.

Our paper explores how direct online booking affects the variation in hotel bed-places net occupancy rate, thereby contributing to three strands of literature, respectively the determinants of seasonality, the tourist information acquisition process and the impact of the internet on tourism. We first model the impact of online booking on seasonality showing that the internet, by reducing search costs, increases the competitive pressure faced by each firm. This raises individual demand elasticity and lowers the prices charged by each firm. As this effect is stronger in the peak period than it is off-peak, we show that online booking actually increases seasonality.

Our empirical findings confirm the causal (positive) relation between online booking and seasonality.

The results in our formal model point at a supply-driven positive association between online booking and seasonality. As a consequence of online booking, firms modify their pricing strategy. The demand side behaviour is altered only indirectly, through the price changes induced by online booking.

While the result of our formal model straightforwardly applies to online direct search only, its intuition could be extended to search mediated by intermediaries and travel agents with online operations. Indeed, online booking fundamentally alters the role of travel agents. The business of traditional travel agents, consisting mainly in aggregating information on the supply side- that is, aggregating the various travel and accommodation options available to the consumers- relied on high costs of direct search, and is likely bound to marginalisation in the near future. On the contrary, opportunities for new businesses arise for online travel agents, who can track customers' online searches and online purchases, and exploit them to provide customers with more tailored offers, by the same principle used by Google and the other search engines. In other words, travel agents are turning to aggregators of information on the demand side. This is likely going to alter the nature of advertising in the tourism sector, towards one tailored on the individual consumer's needs, and mediated by the travel agents. In this scenario, travel agents are going to take the role of two-sided platforms, drawing revenue from two distinct sources, consumers and advertisers. 
An immediate implication of our result is that the various actors in the tourism sector should not simply rely on the Internet as a tool to reduce seasonality; in fact, it is quite the opposite.

Our results call for a series of initiatives, both in a managerial and in a policy perspective, aimed at mitigating the impact of the increased seasonality. Three traditional remedies include a more effective yield management and price dispersion across periods, the organisation of events and festivals able to attract people in the low season, and more scattered holidays (especially in countries where holidays are still very concentrated, such as the Mediterranean ones).

Yield management, price dispersion and even price discrimination may turn out to be easier in the future than they have been traditionally, due to the aforementioned availability of information on the demand side. In this scenario, the jobs of setting prices and capacity utilisation will likely have significant returns to scale, as all the activity implying information aggregation. While our findings show that, on average, the use of internet on average increases seasonality, it is clear that managers might actually use it precisely to try to reduce it. A way through which this task could be achieved include, among others, running auctions among potential customers (on the lines of websites such as priceline.com, or ebay) to determine the price of a hotel room in low season, in order to induce higher occupancy rates.

The de-seasonalisation of destinations, and even of individual hotels and accommodation may also be facilitated by the availability of tailored advertising. This may be an effective mean of informing potential customers of the upgrades and enhancements of the destinations/hotel, also thanks to the efficient rating system for hotels and destinations, performed by customers directly, that has emerged in many online travel agents. An efficient and fluid rating mechanism may also favour information spreading on initiatives on a small scale that contribute to alleviate seasonality.

Furthermore, we have shown that flow concentration increases seasonality. A way to de-seasonalise, therefore, may consist in targeting the new investments of a given destination (for example, in advertising, in infrastructures, or in the organisation of events and festivals) towards countries that, while having a significant potential demand, still account for a low share of tourists in that destination. By doing so, according to our results, the investment, not only would affect the total amount of tourists (and, as a result, the total revenue), but would also alleviate the seasonality problem, thereby contributing to a more efficient allocation of resources.

The rise in seasonality can be attributed to an increase in competitive pressure. A possible direction for future research may consist in analysing the impact on firms' profit. Indeed, it is likely that, while competitive pressure tends to reduce firms' profit, the reduction in search cost also redistributes profits from the intermediation sector (hampered by the development of direct online booking) to the transport/accommodation providers. The direction of the net effect on the transportation/ accommodation providers profit depends on the relative strength of the two forces, and is worth analysing. 
An additional step of this research may consist in verifying to what extent different types of accommodations experience different seasonality phenomena and how much they lag among each other in terms of the adoption and use of Information and Communication Technology. As the Eurostat data do not provide a refined segregation across various types of accommodation and quality levels, a direct survey would probably be the most suitable methodology. A

Acknowledgements - We thank session participants at the Consumer Behavior in Tourism Symposium (CBTS) 2011 held in Bruneck and two anonymous referees. We are also grateful to Daniele Paci, who contributed to an earlier version of this work, Oswin Maurer and Hugo Goetsch for their helpful comments and help in the data collection process.

\section{REFERENCES}

Arellano, M., \& Bond, S. (1991). Some tests of specification for panel data: Monte Carlo evidence and an application to employment equations. Review of Economic Studies, 58, 277-297.

Ashworth, J., \& Thomas, B. (1999). Patterns of seasonality in employment in tourism in the UK. Applied Economics Letters, 6, 735-739.

Bakos, J. Y. (1997). Reducing buyer search costs: Implication for electronic marketplaces. Management Sciences, 43(12).

Bar-On, R. (1975). Seasonality in tourism: A guide to the analysis of seasonality and trends for policy making. London: The Economist Intelligence Unit, Series No. 2.

Bar-On, R. (1993). Seasonality. In M. Khan, M. Olsen, \& T. Var (Eds.), VNR's encyclopedia of hospitality and tourism (pp. 705-734). New York: Van Nostrand Reinhold.

Bar-On, R. (1999). The measurement of seasonality and its economic impacts. Tourism Economics, 5, 437-458.

Baum, T., \& Hagen, L. (1999). Responses to seasonality: The experiences of peripheral destinations. International Journal of Tourism Research, 1, 299-312.

Blundell, R., \& Bond, S. (1998). Initial conditions and moment restrictions in dynamic panel data models. Journal of Econometrics, 87, 115-143.

Butler, R. (1994). Seasonality in tourism: Issues and problems. In A. V. Seaton (Ed.), Tourism: The state of art (pp. 332-339). Chichester: Wiley.

Butler, R., \& Mayo, B. (1996). Seasonality in tourism: Problems and measurement. In P. Murphy (Ed.), Quality management in urban tourism (pp. 9-23). Chichester: Wiley.

Calantone, R., \& Johar, J. (1984). Seasonal segmentation of the tourism market using a benefit segmentation framework. Journal of Travel Research, 23(2), 14-24.

Capò-Parrilla, J., Font, A. R., \& Nadal, J. R. (2006). Accommodation determinants of seasonal patterns. Annals of Tourism Research, 34, 422-436.

Card, J., Chen, C., \& Cole, S. (2003). Online travel products shopping: Differences between shoppers and nonshoppers. Journal of Travel Research, 42(2), 133-139.

Cellini, R., \& Cuccia, T. (2007). Is cultural heritage really important for tourists? A contingent rating study. Applied Economics, 39, 261-271.

Choi, S., Lehto, X. Y., \& Oleary, J. (2007). What does the consumer want from a DMO Website? A study of US and Canadian tourists' perspectives. International Journal of Tourism Research, 9, 59-72.

Cuccia, T., \& Rizzo, I. (2010). Tourism seasonality in cultural destinations: Empirical evidence from Sicily. Tourism Management. doi:10.1016/ j.tourman.2010.05.008.

Dana, J.D., \& Orlov, E. (2009). Internet penetration and capacity utilization in the US Airline Industry. Northeastern U. College of Business Administration Research Paper No. 08-001. Available at SSRN: <http://ssrn.com/ abstract $=1297341>$. 
DiPietro, R. B., Wang, Y., Rompf, P., \& Severt, D. (2007). At destination visitor information search and venue decision strategies. International Journal of Tourism Research, 9, 175-188.

Drakatos, C. (1987). Seasonal concentration of tourism in Greece. Annals of Tourism Research, 14, 582-586.

Engel, J. F., Blackwell, R. D., \& Miniard, P. W. (1995). Consumer behavior (8th ed.). Fort Worth, TX: The Dryden Press.

Engel, J. F., Warshaw, M. R., \& Kinnear, T. C. (1991). Promotional strategy (7th ed.). Boston, MA: Irwin.

EUROCONTROL. (2007). Low-cost carrier market update, June 2007.

Eurostat. (2006). How Europeans go on holiday, statistics in focus, Luxembourg.

Fernandez-Morales, A., \& Mayorga-Toledano, M. C. (2008). Seasonal concentration of the hotel demand in Costa del Sol: A decomposition by nationalities. Tourism Management, 29, 940-949.

Fesenmaier, D. R., \& Jeng, J. (2000). Assessing structure in the pleasure trip planning process. Tourism Analysis, 5, 13-28.

Fodness, D., \& Murray, B. (1997). Tourist information search. Annals of Tourism Research, 24(3), 503-523.

Fodness, D., \& Murray, B. (1998). A typology of tourist information search strategies. Journal of Travel Research, 37, 108-119.

Fodness, D., \& Murray, B. (1999). A model of tourist information search behavior. Journal of Travel Research, 37, 220-230.

Frechtling, D. (1996). Practical tourism forecasting. Oxford: Butterworth-Heinemann.

Garrigos-Simon, Fernando J., Narangajavana, Yeamduan, \& Gil-Pechuan, Ignacio (2010). Seasonality and price behavior of airlines in the Alicante-London market. Journal of Air Transport and Management, 16, 350-354.

Getz, D. (1991). Festivals, special events and tourism. New York: Van Nostrand Reinhold.

Getz, D. (1997). Event management and event tourism. New York: Cognizant.

Gursoy, D., \& Chen, J. S. (2000). Competitive analysis of cross cultural information search behaviour. Tourism Management, 21(6), 583-590.

Gursoy, D., \& McClearly, K. W. (2004). An integrative model of tourists' information search behaviour. Annals of Tourism Research, 31(2), 353-373.

Higham, J., \& Hinch, T. (2002). Tourism, sport and seasons: The challenger and potential of overcoming seasonality in the sport and tourism sectors. Tourism Management, 23, 175-185.

Hinch, T., \& Jackson, E. (2000). Leisure constraints research: Its value as a framework for understanding tourism seasonability. Current Issues in Tourism, 3, 87-106.

Hwang, J. H., \& Fesenmaier, D. R. (2004). Coverage error embedded in selfselected internet based samples: A case study of Northern Indiana. Journal of Travel Research, 42(3), 297-304.

Hyde, K. F. (2008). Information processing and touring planning theory. Annals of Tourism Research, 35(3), 712-731.

Jang, S. (2004). Mitigating tourism seasonality-A quantitative approach. Annals of Tourism Research, 31, 819-836.

Jeffrey, D., \& Barden, R. (1999). An analysis of the nature, causes and marketing implications of seasonality in the occupancy performance of English hotels. Tourism Economics, 5, 69-91.

Jeng, J., \& Fesenmaier, D. R. (2002). Conceptualizing the travel decision-making hierarchy: A review of recent developments. Tourism Analysis, 7, 15-32.

Kandari, O. P., \& Chandra, Ashish (2004). Tourism, biodiversity and sustainable development. Delhi, India: Isha Books.

Kim, S. (2010). The diffusion of the Internet: Trend and causes. Social Science Research. doi:10.1016/j.ssresearch.2010.07.005.

Koenig, N., \& Bischoff, E. (2003). Seasonality of tourism in Wales: A comparative analysis. Tourism Economics, 9, 229-254.

Koenig, N., \& Bischoff, E. E. (2004). Analyzing seasonality in Welsh room occupancy data. Annals of Tourism Research, 31, 374-392.

Koenig-Lewis, N., \& Bischoff, E. E. (2005). Seasonality research: The state of the art. International Journal of Tourism Research, 7, 201-219. doi:10.1002/jtr.531. 
Krakover, S. (2000). Partitioning seasonal employment in the hospitality industry. Tourism Management, 21, 461-471.

Li, Xu., \& Wang, Y. (2010). Evaluating the effectiveness of destination marketing organisations' Websites: Evidence from China. International Journal of Tourism Research, 12, 536-549.

Lundtorp, S. (2001). Measuring tourism seasonality. In T. Baum \& S. Lundtorp (Eds.), Seasonality in Tourism (pp. 23-50). Oxford: Pergamon.

Manning, R., \& Powers, L. (1984). Peak and off-peak use: Redistributing the outdoor recreation/tourism load. Journal of Travel Research, 23(2), 25-31.

McEnnif, J. (1992). Seasonality of tourism demand in the European community. EIU Travel and Tourism Analyst, 3, 67-88.

McIntosh, R. W., \& Goeldner, C. R. (1990). Tourism: Principles, practices, philosophies. New York: Wiley.

Minghetti, V., \& Buhalis, D. (2010). Digital divide in tourism. Journal of Travel Research, 49(3), 267-281.

Morrison, A., Jing, S., O'Leary, J., \& Cai, L. (2001). Predicting usage of the internet for travel bookings: An exploratory study. Information Technology $\mathcal{E}$ Tourism, 4, $15-30$.

Moutinho, L. (1987). Consumer behavior in tourism. European Journal of Marketing, $21,5-44$.

Murphy, P. (1985). Tourism: A community approach. London: Methuen.

O'Driscoll, T. (1985). Seasonality in the Trans-Atlantic vacation market. Annals of Tourism Research, 12, 109-110.

Pan, B., \& Fesenmaier, D. R. (2006). Online information search. Vacation planning process. Annals of Tourism Research, 33(3), 809-832.

Pearce, D. G., \& Schott, C. (2005). Tourism distribution channels: The visitors' perspective. Journal of Travel Research, 44, 50-63.

Raitz, K., \& Dakhil, M. (1989). A note about information sources for preferred recreational environments. Journal of Travel Research, 27(1), 45-49.

Rossellò-Nadal, J., Riera Font, A., \& Rossello, A. (2004). The economic determinants of seasonal patterns. Annals of Tourism Research, 31, 697-711.

Schmidt, J., \& Spreng, R. (1996). A proposed model of external consumer information search. Journal of the Academy of Marketing Science, 24, 246-256.

Sirakaya, E., \& Woodside, A. G. (2005). Building and testing theories of decision making by travellers. Tourism Management, 26(6), 815-832.

Snepenger, D. J., Meged, K., Snelling, M., \& Worrall, K. (1990). Information search strategies by destination-naive tourists. Journal of Travel Research, 29(2), $13-16$.

Sørensen, N. (1999). Modelling the seasonality of hotel nights in Denmark by county and nationality. Tourism Economics, 5, 9-23.

Spencer, D. M., \& Holecek, D. F. (2007). Basic characteristics of the fall tourism market. Tourism Management, 28, 491-504.

Spotts, D., \& Mahoney, E. (1993). Understanding the fall tourism market. Journal of Travel Research, 32(2), 3-15.

Spulber, D. (1996). Market making for price-setting firms. The Review of Economic Studies, 10, 133-152.

Stigler, G. (1961). The economics of information. Journal of Political Economy, 19, 213-225.

Stiglitz, J. (1989). Imperfect information in the product market. In R. Schmalensee \& R. Willig (Eds.), Handbook of industrial organization (1st ed., pp. 769-847). Oxford, UK: Elsevier.

Sutcliffe, C., \& Sinclair, M. (1980). The measurement of seasonality within the tourist industry: An application to tourist arrivals in Spain. Applied Economics, 12(4), 429-441.

Tirole, J. (1988). The theory of industrial organization. Cambridge: MIT Press.

Van Raaij, W. F. (1986). Consumer research on tourism: Mental and behavioral constructs. Annals of Tourism Research, 13, 1-9.

Vogt, C., \& Fesenmaier, D. (1998). Expanding the functional information search. Annals of Tourism Research, 25, 551-578.

Weaver, D., \& Oppermann, M. (2000). Tourism management. Brisbane: Wiley. 
Woo, G. K., \& Dong, J. K. (2004). Factors affecting online hotel reservation intention between online and non-online customers. Hospitality Management, 23, 381-395.

Submitted 1st February 2011. Resubmitted 13th June 2011. Resubmitted 14th October 2011. Final version 13th December 2011. Accepted 22nd January 2012. Refereed anonymously. Coordinating Editor: A. Papatheodorou

Available online at www.sciencedirect.com

\section{SciVerse ScienceDirect}

